\section{Dispositivos ventilatórios não invasivos em criança portadora de amiotrofia espinhal do tipo 1: relato de caso}

\section{Noninvasive ventilation devices in a child with spinal muscular atrophy type 1: a case report}

Paulo André Freire Magalhães 1

Ana Carolina Gusmão d'Amorim 2

Ana Patrícia Mendes 3

Maria Eveline Albuquerque Ramos 4

Lívia Beatriz Santos de Almeida 5

Maria do Carmo Menezes Bezerra Duarte 6

1,6 Programa de Pós-graduação em Saúde Materno Infantil. Instituto de Medicina Integral Prof. Fernando Figueira. Rua dos Coelhos, 300 Boa Vista. Recife, PE, Brasil. CEP: 50.070-550.

E-mail: paulofisiomagalhaes@hotmail.com

2-4 Real Hospital Português de Beneficência em Pernambuco. Recife, PE, Brasil.

${ }^{5}$ Associação de Assistência à Criança Deficiente (AACD). Recife, PE, Brasil.

\section{Resumo}

Introdução: amiotrofia espinhal do tipo 1 (AME

Introduction: the spinal muscular atrophy type 1 (AME1) is an autosomal recessive genetic disorder that promotes cell death of motor neurons located in the anterior horn of the spinal cord and motor nuclei of the brainstem. Early mortality is linked to the bulbar dysfunction and respiratory failure, requiring hospitalization and invasive mechanical ventilation $(I M V)$. The purpose of this study is to promote the maintenance patients with SMA type 1 without invasive ventilation support and individualized physical therapy protocol, improving child's quality of life and integration with their families.

Description: this report relates a child diagnosed with AME1, who at 11 months was admitted and underwent IMV for 76 days, succeeding extubation after respiratory therapy protocol application using cough machine and noninvasive ventilation (NIV).

Discussion: despite the difficulties and complications observed, there was persistence of the proposed assistance, reaching goal of withdrawal of IMV and transfer to home care with noninvasive ventilation devices. The IMV for tracheostomy is considered treatment of choice in Brazil. Notwithstanding, families need to be clarified of the irreversibility of the disease and strategic possibilities of therapeutic strategies (IMV, NIV and palliation) for the management of the child with severe SMA 1.

Key words Airway extubation, Respiration, artificial, Spinal muscular atrophy, Spinal muscular atrophies of childhood
1) é uma doença genética autossômica recessiva que promove morte celular de neurônios motores localizados no corno anterior da medula e núcleos motores do tronco cerebral. A precoce morbimortalidade está associada à disfunção bulbar e insuficiência respiratória, necessitando de internamento hospitalar e de suporte ventilatório artificial. O objetivo do estudo foi divulgar a relevância da manutenção de paciente com AME 1 sem prótese ventilatória invasiva e com protocolo de fisioterapia individualizado, proporcionando melhor qualidade de vida e integração com seus familiares.

Descrição: relato de caso de menor diagnosticado com AME 1 que aos 11 meses foi submetido à ventilação mecânica invasiva (VMI) por 76 dias, obtendo sucesso no desmame após aplicação de um protocolo de fisioterapia respiratória, incluindo a utilização de tosse mecanicamente assistida e ventilação não invasiva (VNI).

Discussão: apesar das dificuldades e intercorrências observadas, a assistência proposta alcançou o objetivo de retirada da VMI e transferência para internação domiciliar com dispositivos ventilatórios não invasivos. A VMI por traqueostomia é considerada tratamento de eleição no Brasil, no entanto, as familias precisam ser esclarecidas da irreversibilidade da doença e das possibilidades estratégicas das terapêuticas atuais (VMI, VNI e paliação) para o manuseio de criança grave com AME 1.

Palavras-chave Extubação, Respiração artificial, Atrofia muscular espinal, Atrofias musculares espinais da infância 


\section{Introdução}

A amiotrofia espinhal (AME) é uma doença genética autossômica recessiva, causada por mutações no gene SMN1, envolvendo a morte celular de neurônios motores localizados no corno anterior da medula e núcleos motores do tronco cerebral. ${ }^{1} \mathrm{Na}$ sua forma mais grave, que é o tipo 1, também conhecida como Doença de Werding-Hoffman, seus portadores apresentam hipotonia grave, fraqueza muscular difusa, arreflexia e incapacidade de sentar sem apoio. A depender do tratamento de eleição e gravidade da doença, a morte geralmente ocorre por insuficiência respiratória entre 12 meses e três anos de idade. ${ }^{2-4}$

\section{Descrição}

Lactente com diagnóstico de AME 1, sexo masculino, 11 meses de vida apresentando insuficiência respiratória aguda foi admitido em um hospital privado de Recife, Pernambuco, Brasil e submetido à intubação orotraqueal (IOT) de urgência. Após oito dias de IOT foi submetido à traqueostomia (TQT) eletiva. No $22^{\circ}$ dia de assistência ventilatória mecânica invasiva (VMI) a criança apresentou descompensação respiratória com necessidade de substituição da TQT por tubo orotraqueal (TOT).

Não foram encontradas alterações anatômicas na traqueia após a avaliação da equipe de cirurgia torácica, e diante da recusa dos seus responsáveis legais para uma nova traqueostomia, o menor permaneceu em VMI com o TOT.

Após 76 dias de internamento foi avaliado o check list de desmame da VMI: administração de corticóide por 72 horas (dexametasona $4 \mathrm{mg}$, via endovenosa, de 6 em 6 horas, em bolus); sem alterações significativas na radiografia $(\mathrm{RX})$ do tórax; gasometria adequada; e teste de respiração espontânea (TRE) em pressão de suporte ventilatório (PSV) positivo de $7 \mathrm{cmH}_{2} \mathrm{O}$ por 30 minutos. $\mathrm{E}$ então realizado extubação traqueal com sucesso. $\mathrm{O}$ menor permaneceu estável por $24 \mathrm{~h}$ em ventilação não invasiva (VNI) via interface nasal (Figura 1), modo assistido controlado (A/C), com os seguintes parâmetros: pressão positiva inspiratória (PIP): 20 $\mathrm{cmH}_{2} \mathrm{O}$; pressão positiva expiratória final (PEEP): 6 $\mathrm{cmH}_{2} \mathrm{O}$; fração inspirada de oxigênio $\left(\mathrm{FiO}_{2}\right): 21 \% \mathrm{e}$ frequência respiratória (FR): 18ipm.

As sessões de fisioterapia seguiram um protocolo individualizado elaborado pelos autores em colaboração com a equipe multiprofissional envolvida neste caso: (1) tosse mecanicamente assistida (TMA) com o aparelho Cough Assist (Philips Respironics, Murrysville, PA, EUA), a técnica consistiu em cinco ciclos de Insuflação e Exsuflação Mecânica (MI-E) com pressões de $+40 \mathrm{cmH}_{2} \mathrm{O}$ e -40 $\mathrm{cmH}_{2} \mathrm{O}$ respectivamente, associados à aceleração do fluxo expiratório (AFE) e aspiração nasotraqueal; (2) terapia de expansão pulmonar (TEP) através da elevação e tracionamento dos membros superiores até a estabilização da saturação periférica de oxigênio $\mathrm{SpO}_{2}(\geq 92 \%)$ e VNI com aumento da PIP em $5 \mathrm{cmH}_{2} \mathrm{O}$ por 10 minutos, seguindo de redução de 1 em $1 \mathrm{cmH}_{2} \mathrm{O}$ a cada cinco ciclos respiratórios. (3) posicionamento em prono e VNI durante o sono (PIP: $20 \mathrm{cmH}_{2} \mathrm{O}$; PEEP: $6 \mathrm{cmH}_{2} \mathrm{O}$; $\mathrm{FiO}_{2}$ : 21\%; FR: 18 ipm) (Tabela 1).

Figura 1

Criança com uso de ventilação mecânica não invasiva via interface nasal.

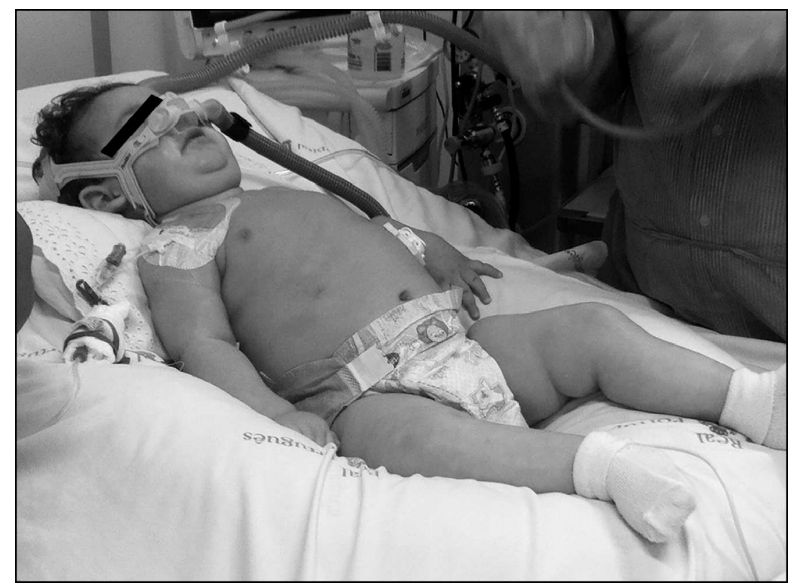


Protocolo de fisioterapia respiratória para criança portadora de amitrofia espinhal do tipo 1 elaborado pelos autores, com a colaboração da equipe multiprofissional envolvida no caso relatado.

\begin{tabular}{|c|c|c|c|}
\hline Fases & Técnica & Parâmetros/Descrição & $\begin{array}{l}\text { Número de repetições/ } \\
\text { Tempo de aplicação }\end{array}$ \\
\hline Fase 1 & $\begin{array}{l}\text { Tosse assistida } \\
\text { mecanicamente (Cough }\end{array}$ & Insuflação $+40 \mathrm{cmH}_{2} \mathrm{O}$ e Exsuflação- $40 \mathrm{cmH}_{2} \mathrm{O}$ & $\begin{array}{l}\text { Cinco ciclos de Insuflação e } \\
\text { Exsuflação Mecânica }\end{array}$ \\
\hline \multirow[t]{3}{*}{ Terapia Desobstrutiva } & $\begin{array}{l}\text { Assist; Philips Respironics, } \\
\text { Murrysville, PA, EUA) }\end{array}$ & & \\
\hline & $\begin{array}{l}\text { Aceleração de fluxo } \\
\text { expiratório (associada à fase } \\
\text { exsuflatória do Cough } \\
\text { Assist) }\end{array}$ & $\begin{array}{l}\text { Movimento tóracoabdominal sincronizado, } \\
\text { gerado pelas mãos do fisioterapeuta sobre o } \\
\text { tempo expiratório que se inicia após o platô } \\
\text { inspiratório }\end{array}$ & Cinco \\
\hline & Aspiração nasotraqueal & $\begin{array}{l}\text { Sucção no trato respiratório por meio de uma } \\
\text { sonda via nasotraqueal }\end{array}$ & $\begin{array}{l}\text { Proporcional à quantidade } \\
\text { de secreção }\end{array}$ \\
\hline Fase 2 & $\begin{array}{l}\text { Tracionamento torácico } \\
\text { manual }\end{array}$ & $\begin{array}{l}\text { Elevação e tracionamento dos membros } \\
\text { superiores após apiração nasotraqueal }\end{array}$ & Cinco \\
\hline \multicolumn{4}{|l|}{ Terapia Reexpansiva } \\
\hline & $\begin{array}{l}\text { Terapia de expansão } \\
\text { pulmonar com pressão } \\
\text { positiva }\end{array}$ & $\begin{array}{l}\text { Aumento da Pressão Positiva Inspiratória em } 5 \\
\mathrm{cmH}_{2} \mathrm{O}: 25 \mathrm{cmH}_{2} \mathrm{O}\end{array}$ & $\begin{array}{l}\text { Tempo de aplicação de } 10 \\
\text { minutos, sendo diminuída de } \\
1 \text { em } 1 \mathrm{cmH}_{2} \mathrm{O} \text { a cada } 5 \text { ciclos } \\
\text { respiratórios }\end{array}$ \\
\hline \multirow[t]{2}{*}{$\begin{array}{l}\text { Assistência Mecânica } \\
\text { Ventilatória Não } \\
\text { Invasiva }\end{array}$} & $\begin{array}{l}\text { Ventilação mecânica não } \\
\text { invasiva com pressão } \\
\text { positiva via interface nasal, } \\
\text { modo assistido controlado } \\
\text { (A/C) }\end{array}$ & $\begin{array}{l}\text { Pressão Positiva Inspiratória: } 20 \mathrm{cmH}_{2} \mathrm{O} \text {; Pressão } \\
\text { Poisitiva Expiratória Final: } 6 \mathrm{cmH}_{2} \mathrm{O} \text {; fração } \\
\text { inspirada de oxigênio: } 21 \% \text { e frequência } \\
\text { respiratória: } 18 \mathrm{ipm}\end{array}$ & $\begin{array}{l}\text { Durante o sono } \\
\text { (aproximadamente } 8 \text { horas) }\end{array}$ \\
\hline & Drenagem Postural & Criança posicionada em prona & $\begin{array}{l}\text { Durante o sono } \\
\text { (aproximadamente } 8 \text { horas) }\end{array}$ \\
\hline
\end{tabular}

Após 24 horas da extubação, a VNI foi suspensa depois de discussão com a equipe multidisciplinar. O menor evoluiu com desconforto respiratório, espasticidade e queda de $\mathrm{SpO}_{2}(75-85 \%)$. Foi administrado três ciclos de salbutamol por via inalatória, melhorando o padrão ventilatório e estabilização da $\mathrm{SpO}_{2}$ $(>92 \%)$. Passando-se dez horas, o menor apresentou novo episódio de broncoespasmo e queda de $\mathrm{SpO}_{2}$ (78-86\%), repetiu-se o uso de salbutamol e ajustes da VNI para PIP: $24 \mathrm{cmH}_{2} \mathrm{O}$ e PEEP: $8 \mathrm{cmH}_{2} \mathrm{O}$. No dia seguinte foi realizada gasometria arterial $(\mathrm{pH}$ : 7,43; $\mathrm{pCO}_{2}: 29,8 \mathrm{mmHg} ; \mathrm{pO}_{2}: 52,3 \mathrm{mmHg} ; \mathrm{HCO}_{3}$ : $19,5 \mathrm{mEq} / \mathrm{L} ; \mathrm{BE}:-4 ; \mathrm{SatO}_{2}: 90 \%$ ) e RX de tórax que foi normal.

No $3^{\circ}$ dia pós extubação o desmame da VNI foi iniciado e o menor passou um período de uma hora por dia, duas vezes ao dia respirando espontaneamente (RE), sendo planejado desmame da VNI até um tempo total de cinco horas em RE, duas vezes ao dia. Neste dia ( $3^{\circ}$ dia pós extubação) os exames laboratoriais evidenciaram quadro infeccioso bacteriano, sendo diagnosticada infecção relacionada à assistência a saúde. Realizado antibioticoterapia com ciprofloxacino por 14 dias.

No $5^{\circ}$ dia pós-extubação, o desmame foi novamente suspenso devido pneumotórax à esquerda após punção venosa central, para tal, foi feito drenagem torácica (DT) com colocação de dreno torácico em selo d'água. O RX de tórax após a DT evidenciou atelectasia em lobo médio do pulmão 
direito. $\mathrm{O}$ lactente foi posicionado em prona e realizou-se TEP com otimização da PEEP $\left(8 \mathrm{cmH}_{2} \mathrm{O}\right)$, sendo evidenciada resolução da atelectasia no RX de tórax do dia seguinte. Neste dia, o menor não foi colocado em RE e o uso da TMA foi temporariamente suspenso. Por decisão da equipe multidisciplinar, nos dois dias seguintes a VNI foi utilizada de forma contínua. No segundo dia pós-punção, durante infusão de concentrado de hemácias, o menor evoluiu com queda de $\mathrm{SpO}_{2}$ (76-82\%), pele mosqueada e desconforto respiratório. Foi aumentada a PIP para $20 \mathrm{cmH}_{2} \mathrm{O}$ estabilizando a $\mathrm{SpO}_{2}$ $(>92 \%)$. No $3^{\circ}$ dia pós-punção foi reiniciado o desmame da VNI com RE por 1:30h, duas vezes ao dia, aumentando o tempo de RE para 2:30h e depois para 3:30h. A PIP foi reajustada para $18 \mathrm{cmH}_{2} \mathrm{O}$. No $3^{\circ}$ dia após o reinício do desmame a criança foi desconectada da VNI durante o dia e reconectada à noite e durante o sono vespertino. No dia seguinte reduziu-se a PIP para $16 \mathrm{cmH}_{2} \mathrm{O}$ e a PEEP para 6 $\mathrm{cmH}_{2} \mathrm{O}$.

As sessões de fisioterapia seguiram nos dias seguintes sem intercorrências, a VNI foi estabelecida por duas horas durante o dia, independente do sono. Após 14 dias foi solicitado internamento domiciliar e iniciado o treinamento dos familiares. Os exames de rotina foram considerados adequados ( $\mathrm{Hb}: 11,2$; Leucócitos: 8.680; PLT: 413.000; PCR: 0,196; gasometria $\mathrm{pH}: 7,46 ; \mathrm{pCO}_{2}: 32,4 \mathrm{mmHg} ; \mathrm{pO}_{2}$ : $86,8 \mathrm{mmHg} ; \mathrm{HCO}_{3}: 22,7 \mathrm{mEq} / \mathrm{L} ; \mathrm{BE}:-0,1 ; \mathrm{SPO}_{2}$ : 96,9\%). Após 131 dias de internamento, a criança foi transferida para internamento domiciliar com os mesmos parâmetros ventilatórios e protocolo da fisioterapia (Tabela 1).

Radiografia após sete meses da extubação revelou pulmões com boa expansibilidade, sem alterações significativas (Figura 2), e murmúrios vesiculares universalmente audíveis através da ausculta pulmonar.

Após oito meses da alta hospitalar, a criança tinha três anos e um mês e permanece em internamento domiciliar de alta complexidade com acompanhamento fisioterapêutico duas vezes ao dia, sem necessitar hospitalizações. Utiliza a TMA (cinco ciclos de MI-E: $+40 \mathrm{cmH}_{2} \mathrm{O} ;-40 \mathrm{cmH}_{2} \mathrm{O}$ ) e VNI apenas durante o sono mais duas horas durante o dia (PIP: $20 \mathrm{cmH}_{2} \mathrm{O}$; PEEP: $6 \mathrm{cmH}_{2} \mathrm{O}$; $\mathrm{FiO}_{2}$ : 21\%; FR: 18ipm).

\section{Discussão}

Estudos descrevem que a progressão do comprometimento muscular em portadores de AME 1 é rápida em função da gravidade da doença. Verifica-se intensa destruição de neurônios motores inferiores, degeneração dos axônios motores das raízes anteriores e profunda atrofia neurogênica dos músculos, inclusive da musculatura respiratória. Na maioria dos casos, a expectativa de vida é curta, dificilmente ultrapassando o terceiro ano de vida.1,4 No entanto, pacientes com AME 1 são geralmente estáveis até que ocorram complicações respiratórias e disautonomia. A insuficiência respiratória aguda é devido a fraqueza e fadiga dos músculos respiratórios, bem como pela incapacidade de tossir de forma eficaz, o que dificulta o clareance mucociliar e facilita a recorrência de pneumonias. O caso em estudo apresentou sinais clássicos de insuficiência respiratória aos 11 meses de idade, concordando com os dados reportados na literatura. $2,3,5$

\section{Figura 2}

Raio-x de tórax após 7 meses de extubação orotraqueal.

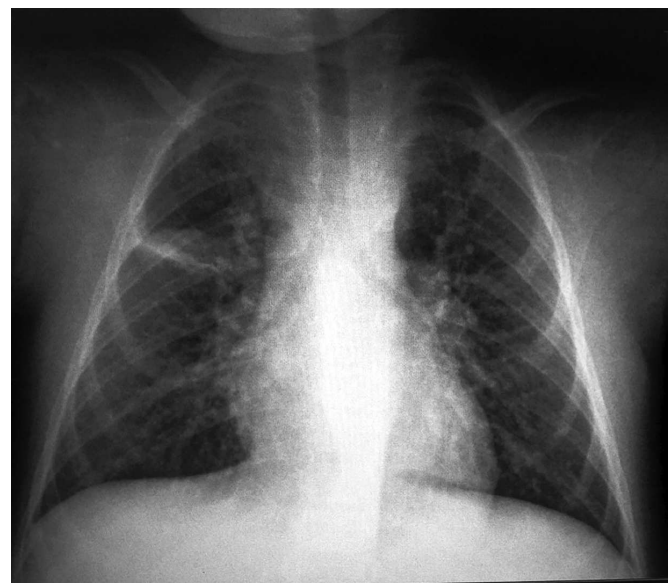


Estudos relatam diferentes formas de tratamento para portadores de AME 1: VMI com traqueostomia, VNI e seguimento do curso natural da doença (paliação).1,2,6 Na Austrália, um estudo retrospectivo de auditoria clínica envolvendo 35 crianças durante o período de 2005 a 2010 verificou que apenas $26 \%$ delas foram ventiladas invasivamente por um período $<90$ dias e apenas duas foram intubadas após confirmação do diagnóstico. Limites "mínimos e máximos" do plano de cuidados de terminalidade de vida (alimentação por sonda nasográstrica, fluidos, admissão em UTI, sedação e analgesia) foram discutidos em 74,3\% dos casos, sendo que em 19 lactentes, os desejos dos pais foram explicitados em prontuários, incluindo não reanimar. As crianças morreram por insuficiência respiratória em $82,7 \%$, com documentação em prontuário. 3

Outro estudo retrospectivo realizado na Itália envolvendo 194 pacientes e comparando estas três estratégias terapêuticas (VMI, VNI e paliação), verificou que $62,3 \%$ dos casos foram tratados com paliação, $21,7 \%$ com VMI e $16 \%$ com VNI e TMA. Além disso, a escolha da VNI aumentou de $8,1 \%$ (1999-2004) para 22,7\% (2005-2010) com diferença significativa. Ademais, os autores relataram a possibilidade de vieses de informação, pois não se sabe se no manejo da VNI, os valores pressóricos estavam adequados, se todos os profissionais eram qualificados para tal, bem como se fisioterapia respiratória foi realizada de forma contínua, atendendo as necessidades e limitações individuais de cada menor avaliado. 2

No Brasil, na literatura pesquisada encontramos apenas relatos de caso e o tratamento de escolha foi a VMI por TQT, porém essa escolha reduz qualidade de vida e pode levar a morte em fase precoce. $7,8 \mathrm{~A}$ presença de prótese ventilatória como a traqueostomia pode lesar diretamente a mucosa da via aérea causando ulceração, inflamação, edema e

\section{Referências}

1. Iascone DM, Henderson CE, Lee JC. Spinal muscular atrophy: from tissue specificity to therapeutic strategies. F1000Prime Rep. 2015;7:4

2. Gregoretti C, Ottonello G, Chiarini Testa MB, Mastella C, Ravà L, Bignamini E, Veljkovic A, Crutera R. Survival of patients with spinal muscular atrophy type 1 . Pediatrics. 2013; 131 (5): 1509-14.

3. Tassie B, Isaacs D, Kilham H, Kerridge I. Management of children with spinal muscular atrophy type 1 in Australia. J Paediatr Child Health. 2013; 49 (10): 815-9. hemorragia submucosa, e em casos extremos, estenose da via aérea. Adicionalmente, a via aérea artificial altera os mecanismos naturais de defesa, predispondo a infecções relacionadas à assistência a saúde. Ainda, promove dor e desconforto, impede a alimentação por via oral e a fala. Tais fenômenos impõem a necessidade de sedação em alguns casos e são responsáveis por sérios transtornos psicológicos. 2,9

Em contrapartida, a VNI tem sido considerada uma alternativa viável à VMI convencional em pacientes com AME 1 por reduzir o trabalho muscular respiratório e melhorar a troca gasosa por recrutamento de alvéolos hipoventilados. Além disso, mantém as barreiras de defesa natural, diminui a necessidade de sedação, reduz o período de ventilação mecânica, e ainda pode evitar a intubação orotraqueal, a TQT, e suas complicações.2,6,9,10

No presente relato, observou-se que a atuação da fisioterapia na AME 1 e o uso de dispositivos respiratórios auxiliares não invasivos apresentaram resultados satisfatórios, permitindo a transferência da criança para internamento domiciliar, superando inclusive a expectativa de vida reportada na literatura. Outros estudos também demonstraram que o uso de VNI está associado com menos hospitalizações, liberdade de uso diurno do ventilador, e a capacidade de falar. 9,10

Este estudo pretendeu divulgar a relevância de manter crianças com AME 1 sem VMI por traqueostomia, através de acompanhamento de equipe multidisciplinar e de um protocolo de fisioterapia individualizado, para proporcionar uma melhor qualidade de vida e interação com seus familiares. As famílias precisam ser esclarecidas da irreversibilidade da doença e das possibilidades estratégicas das terapêuticas atuais (VMI, VNI e paliação) para o manuseio de criança grave com AME1.
4. Finkel RS, McDermott MP, Kaufmann P, Darras BT, Chung WK, Sproule DM, Kang PB, Foley AR, Yang ML, Martens WB, Oskoui M, Glanzman AM, Flickinger RS, Montes J, Dunaway S, O'Hagen J, Quiqley J, Riley S, Benton M, Ryan PA, Montgomery M, Marra J, Gooch C, De Vivo DC. Observational study of spinal muscular atrophy type I and implications for clinical trials. Neurology. 2014; 83:810-7.

5. Gray K, Isaacs D, Kilham H a., Tobin B. Spinal muscular atrophy type I: Do the benefits of ventilation compensate for its burdens? J Paediatr Child Health. 2013; 49 (10): $807-$ 12. 
6. Bach JR, Niranjan V, Weaver B. Spinal muscular atrophy type 1: A noninvasive respiratory management approach. Chest. 2000; 117 (4): 1100-5.

7. Lima MB De, Orrico KF, França AP. Atuação da fisioterapia na doença de Werdnig- Hoffmann : relato de caso. Rev Neurocienc. 2010; 18 (1): 50-4.

8. Silva MCV, Pryzsiezny A, Capellani OJ. Síndrome de Werdnig-Hoffman (amiotrofia espinal do tipo 1): relato de caso. Arq Catarin Med. 2013; 42 (1): 96-9.
9. Bach JR, Gonçalves MR, Hon A, Ishikawa Y, De Vito EL, Prado F, Dominiquez ME. Changing trends in the management of end-stage neuromuscular respiratory muscle failure: recommendations of an international consensus. Am J Phys Med Rehabil. 2013; 92 (3): 267-77.

10. Bach JR, Gonçalves MR, Hamdani I, Winck JC. Extubation of patients with neuromuscular weakness: a new management paradigm. Chest. 2010; 137 (5): 1033-9.

Recebido em 10 de abril de 2015

Versão final apresentada em 1 de setembro de 2015

Aprovado em 1 de outubro de 2015 